\title{
TRES LIBROS SOBRE LA GUERRA ESTADOS UNIDOS DE AMÉRICA-MÉXICO
}

RESUMEN: El 2 de febrero del 2001 se cumplieron 153 años de la firma del Tratado de Guadalupe Hidalgo que puso fin a la guerra de los Estados Unidos de América contra México y por el cual nuestro país cedió casi el 51\% de su territorio. Existe una amplia bibliografía sobre éste dramático acontecimiento, pero curiosamente se desconoce a nivel general la trama histórica, quizás porque para México ha sido el episodio más frustrante de su historia, y por ello las referencias sobre aquella época se han quedado en las evocaciones de la leyenda. De ahí que el Área de Derecho Internacional del Instituto de Investigaciones Jurídicas haya convocado a realizar un análisis sobre tres obras significativas: Diario del presidente Polk (1845-1849) (James K. Polk), quien declaró la Guerra a México; Apuntes para la guerra México-Estados Unidos, escrito en 1848 por un conjunto de intelectuales y políticos, testigos y actores de la contienda; y En defensa de la patria, libro conmemorativo del 150 aniversario de la guerra, publicado por el Archivo General de la Nación, y editado por Patricia Galeana. Las tres colaboraciones, al reseñar los libros, recrean el acontecer de la guerra de1846-1848.

ABSTRACT: On February 2, 2001 it was the 153th anniversary of the celebration of the Treaty of Guadalupe Hidalgo which ended the war between the United States and Mexico, whereby Mexico ceded 51\% of national territory. Even when there is wide bibliography on the topic, the history of the matter is not widely known. Perhaps because this has been one of the most frustrating episodes in national history, the memories of that time have remained only in legends. That is why the International Law Department in the Legal Research Institute convoked the community to make an analysis of three main works: Diary of president Polk (1845-1849) (James K. Polk), who declared war on Mexico; Notes on the war Mexico-United States, written in 1848 by a group of politicians who witnessed the conflict; and In Defence of the Country a memory of the 150th anniversary of the conflict, published by the National General Archive, and edited by Patricia Galeana. The next three book reviews depict the events of the war from 1846 to 1848 .

RESUMÉ: Le 2 février 2001 était le 153ème anniversaire de la signature du Traité de Guadalupe Hidalgo, qui a mis fin à la guerre des Etats-Unis contre le Mexique, et par lequel notre pays a cédé pratiquement $51 \%$ de son territoire. Il existe une vaste bibliographie sur ce dramatique événement, mais curieusement la trame historique est généralement mal connue, peut-être parce que pour le Mexique cela a constitué un épisode frustrant de son histoire et donc les références sur cette époque n'ont été que des évocations de légende. C'est pourquoi, le Département de Droit International de l'Institut de Recherches Juridiques a entrepris d'effectuer une analyse sur trois ouvrages très significatifs: Diario del presidente Polk (1845-1849), (James K. Polk), qui a déclaré la guerre au Mexique, Apuntes para la guerra México-Estados Unidos, écrit en 1848 par un certain nombre d'intellectuels et politiciens, témoins et acteurs de la lutte et En defensa de la patria, ouvrage commémoratif du 150 anniversaire de la guerre, publié par l'Archivo General de la $\mathrm{Na}$ ción, et édité par Patricia Galeana. Les trois analyses, en résumant les livres, recréent la situation de la guerre de 1846-1848. 
DIARIO DEL PRESIDENTE POLK (1845-1849)*

Marta MORINEAU**

SUMARIO: I. Introducción. II. James Knox Polk. III. El Diario del presidente Polk. IV. Luis Cabrera, traductor del Diario del presidente Polk.

\section{INTRODUCCIÓN}

El tema central de este artículo es la traducción de algunos pasajes del Diario del presidente Polk, quien gobernó a Estados Unidos de América entre los años de 1845 a 1849. Antes de abordar ese tema en concreto, la segunda parte del trabajo trata acerca de la vida y la actividad política del presidente, la tercera parte está dedicada a su diario, y la cuarta y última parte contiene algunos datos de la vida y la obra de Luis Cabrera, cuya traducción del Diario del presidente Polk fue la que se utilizó en la redacción de este estudio.

\section{JAMES KNOX POLK}

\section{Datos biográficos}

James Knox Polk fue el undécimo presidente de Estados Unidos de América, de 1845 a 1849.

Nació en Carolina del Norte, el 2 de noviembre de 1795, y fue un hombre de frontera, ya que a la edad de once años, junto con su familia, emigró al vecino estado de Tennessee, formando parte de aquellos pioneros americanos que emigraron hacia el oeste de Estados Unidos de América para poblar esas tierras, lo cual dio comienzo a la expansión occidental del país.

* Diario del presidente Polk (1845-1849), recop., pról. y notas de Luis Cabrera, México, Antigua Librería Robredo, 1948, 2 vols. (reproducción de todos los asientos relativos a México, tomados de la edición completa de M. M. Quaife con numerosos documentos anexos relacionados con la guerra entre México y Estados Unidos de América). Una versión preliminar de este artículo fue leída en una sesión de trabajo del Área de Derecho Internacional del Instituto de Investigaciones Jurídicas de la UNAM, organizada por el doctor Ricardo Méndez Silva, el 2 de febrero de 2001.

** Investigadora del Instituto de Investigaciones Jurídicas de la UNAM. 
La mala salud, de niño y de adolescente, impidió que el joven Polk tuviera una educación formal, y no fue sino hasta que cumplió los veinte años que presentó con éxito los exámenes de admisión para ingresar a la Universidad de Carolina del Norte. En esta institución, el joven Polk es recordado como un estudiante correcto, puntual y esforzado. Se distinguió tanto en estudios clásicos como en matemáticas. En 1818, terminó sus estudios con honores, y fue escogido para hablar a nombre de su clase en la ceremonia de graduación.

De regreso a Tennessee, inició los estudios de derecho en el bufete jurídico de Félix Grundy, ${ }^{1}$ en la ciudad de Nashville, hoy capital del estado. Fue admitido a la barra en 1820, al mismo tiempo que iniciaba su carrera política, relacionándose con las figuras públicas locales, y consagrándose como un orador político, popular y populista, descrito por sus contemporáneos como el "Napoleón de la tribuna".

Fue un demócrata convencido y un amigo fiel de Andrew Jackson, quien lo antecedió en la presidencia de su país al ocupar ese cargo, durante dos periodos presidenciales, como el séptimo presidente de Estados Unidos de América, entre los años de 1828 a 1836, y que posteriormente apoyaría a Polk en su camino a la Casa Blanca.

Los Polk ocuparon la residencia oficial del presidente de Estados Unidos de América, en décimo lugar, según el orden cronológico de los presidentes americanos. El primer Congreso autorizó al primer presidente, George Washington, para escoger en las riberas del río Potomac el lugar donde se establecería la capital federal. Washington no sólo cumplió el encargo, sino que además supervisó los planos de la ciudad y de la residencia oficial, que sería ocupada más tarde por los presidentes americanos. No le tocó a Washington vivir en esta casa, ya que los primeros en hacerlo fueron el segundo presidente John Adams y su esposa, en noviembre de 1800, cuando el Congreso se reunió por primera vez en la nueva ciudad.

La alusión al color de la residencia presidencial no es metafórica. El nombre de Casa Blanca comenzó a utilizarse en el año de 1809 por el color blanco de la piedra caliza que se empleó en su construcción, que contrastaba con el ladrillo rojo de los otros edificios, públicos y privados, que la circundaban.

1 La enseñanza del derecho, en esa época y especialmente en esa región del país, tenía usualmente un carácter artesanal, los futuros abogados aprendían el oficio en el bufete de algún abogado que hubiera ya pasado los exámenes de la barra, y se encontrara practicando la profesión. 
Polk se casó en 1824 con Sarah Childress, quien pertenecía a una familia acomodada y bien relacionada de la capital del estado, la cual durante los veinticinco años de vida matrimonial, hasta la muerte de Polk en 1849, fue una leal compañera, apoyándolo siempre en la vida privada y en la pública.

Sus biógrafos dicen que Polk fue, por naturaleza, un estudioso del gobierno; por experiencia, un legislador; y por las circunstancias de la vida, un administrador. De carácter introvertido y rígido, no era fácil acercársele, como tampoco era fácil quererlo, conocía a mucha gente pero tuvo pocos amigos.

\section{Gestión política}

Su primer cargo fue el de diputado local en Tennessee; después fue diputado federal durante catorce años, de 1825 a 1839; y se desempeñó como presidente de la cámara los últimos cuatro años, de 1835 a 1839.

Al dejar al Congreso, lanzó su candidatura y ganó la elección de gobernador de su estado, por un solo periodo, ya que falló dos veces en su intento por buscar la reelección. Tras este fracaso decidió volver a Washington con la esperanza de reanimar su carrera política.

Su nominación como candidato a la Presidencia, en la convención del Partido Demócrata celebrada en la ciudad de Baltimore, en 1844, fue coyuntural, o sea, que no la buscó expresamente, pues había otros miembros del partido que tenían más posibilidades de ocupar el cargo. Sin embargo, por las diferencias entre ellos, se planteó la necesidad de buscar un candidato de compromiso, con la idea de enfocar la campaña en el programa político, más que en la persona del candidato, de tal forma la nominación recayó en Polk, el primer "caballo negro" en una contienda presidencial.

Los resultados de la elección fueron cerrados, pero de cualquier modo, Polk obtuvo 170 votos electorales, contra 105, de su contrincante, Henry Clay, fundador del partido de los whigs. ${ }^{2}$

2 La historia de los partidos políticos americanos es compleja. Durante la presidencia de George Washington, su secretario de Hacienda, Alexander Hamilton, ideó una política fiscal que no fue bien recibida por todos los protagonistas públicos del momento, provocando una división de opiniones que daría lugar a un incipiente sistema de partidos. La oposición encabezada por Jefferson y Madison, tercer y cuarto presidentes respectivamente, adoptó el nombre de "republicanos", en oposición a "monárquicos", insinuación efectiva políticamente, a pesar de que ni Washington ni Hamilton favorecieran un gobierno monárquico. Este partido, en los siguientes años, con diferentes nombres, bajo la presidencia de Andrew Jackson, iniciada en 1828, adoptó el de partido demócrata. El partido de los whigs apareció en 1834 como oposición a los demócratas y finalmente se convirtió en el actual partido republicano, a partir de la presidencia de Lincoln, iniciada en 1860. 
Polk tomó posesión de la Presidencia, cuando todavía no contaba con cincuenta años, lo que lo convirtió en el presidente más joven hasta ese momento. Los temas centrales de su campaña fueron la anexión de Texas a la Unión y el problema de Óregon, que tenía que ver con la frontera entre Estados Unidos de América y Canadá, provincia que todavía pertenecía a la corona inglesa.

Ese problema no era nuevo, el investigador Lawrence Hansen, del Departamento de Estudios de América, en El Colegio de la Frontera Norte, ${ }^{3}$ señala que se remonta a la guerra de Independencia, cuando el recién formado país de las trece colonias trató de apoderarse de aquella provincia. Con Andrew Jackson, la política expansionista y la noción de "destino manifiesto" llegaron a su máxima expresión, con la justificación de no permitir que otras naciones se apoderaran del Continente.

No debe extrañarnos que Polk, protegido político de Jackson, adoptara sus ideas, lo que explica su concepción de los problemas internacionales que afectaban a su país en ese momento. En el sur, Texas contra México y en el noroeste, Óregon contra la Gran Bretaña.

En su discurso inaugural, pronunciado el 4 de marzo de 1845, Polk afirmó que Estados Unidos de América tenía derecho sobre Óregon y solicitó al Congreso que permitiera aumentar las fuerzas armadas en la región, pero como el Congreso no hizo nada al respecto, el presidente se vio obligado a aceptar el tratado de 1846, que dividió el territorio de Óregon entre Estados Unidos de América y Canadá, poniendo fin al conflicto con una solución pacífica.

Con México, los acontecimientos siguieron otro camino. En mayo de 1846 se iniciaron las hostilidades, que, como ya sabemos, terminaron con una victoria para nuestro vecino del norte, y su expansión hacia el sur. Es posible buscar diferentes razones para explicar este resultado, entre otras, quizá la principal, que México representó un enemigo mucho más débil que la Gran Bretaña, ya que no contaba con una cobertura militar como la inglesa.

Una vez concluido su periodo presidencial, en 1849, Polk regresó a su estado natal para establecerse en la ciudad de Nashville, en donde murió meses después el 5 de junio de ese mismo año.

3 Hansen, Lawrence y Taylor, Douglas, "El intento estadunidense de apoderarse de Canadá durante la administración del presidente Polk, 1845-1849”, Secuencia, Revista de Historia y Ciencias Sociales, México, Instituto Mora, nueva época, núm. 33, septiembre-diciembre de 1999, pp. 27-46. 
Lo más significativo de su Presidencia fue la gran expansión territorial de Estados Unidos de América en esos cuatro años, y aunque los historiadores de su país, salvo, alguna excepción, ${ }^{4}$ no lo han colocado en un lugar prominente, no se puede dudar que al final de su gestión, Estados Unidos de América emergiera como una potencia mundial.

\section{EL DIARIO DEL PRESIDENTE POLK ${ }^{5}$}

Don Luis Cabrera explica que su traducción del Diario del presidente Polk abarca aquellos pasajes en los que el presidente se refiere a México. El traductor añade que concibió esta obra "como contribución al centenario de nuestra máxima tragedia nacional", 6 que, entre paréntesis, actualmente rebasa los cien años, pues hasta 2001 ya han transcurrido ciento cincuenta y tres; en otras palabras, hace casi tres años, en 1998, se cumplieron ciento cincuenta años de esa fecha, no sólo triste, sino, a mi modo de ver, también vergonzosa.

El primer volumen de la obra que venimos comentando contiene: prólogo del traductor, prefacio y boceto biográfico de Polk, escritos por Milo Milton Quaife, a cuyo cuidado estuvo la versión inglesa del diario, publicada en cuatro volúmenes y que apareció en Estados Unidos de América, en 1910; una introducción de Andrew Cunningham McLauglin, historiador americano y profesor de la Universidad de Chicago, así como un índice cronológico de la guerra. A continuación siguen los pasajes del diario, seleccionados y traducidos por Luis Cabrera, y sistematizados en tres partes. La primera contiene las entradas de Polk escritas antes de la guerra: de agosto 26 de 1845 a mayo 9 de 1846; la segunda parte corresponde a los años de guerra: de mayo 9 de 1846 a febrero 19 de 1848; y la tercera se refiere a anotaciones, hechas por el presidente, después de la guerra: del 20 de febrero de 1848 al 3 de marzo de 1849. Este volumen acaba con un índice alfabético.

4 Véase Holladay Latané, John, A history of the United States, EUA, Allyn and Bacon, 1924, p. 296, quien señala que el programa político de Polk fue un programa sólido, y que además realizó con éxito; por otro lado, agrega que condujo a su partido con una voluntad férrea.

5 Para un análisis más acucioso del diario, véase Iglesias, Román y Morineau, Marta, "La anexión de Texas a Estados Unidos y la guerra con México, según el diario del presidente Polk”, en varios autores, Liber ad honorem Sergio García Ramírez, México, UNAM, Instituto de Investigaciones Jurídicas, 1998, t. I, pp. 321-347.

6 "Prólogo del traductor", El diario del presidente Polk (1845-1849), nota 1, vol. I, p. IX. 
Al segundo volumen lo considera Cabrera como un complemento del diario, ya que incluye la traducción de documentos que son citados por Polk o que se relacionan estrechamente con los acontecimientos de la guerra; don Luis nos dice:

El segundo volumen de esta obra estará por consiguiente destinada a reproducir los documentos oficiales relacionados con el Diario del presidente Polk, y con el curso de la guerra.

Fue para nosotros un verdadero problema editorial resolver el orden en que debieran insertarse esos documentos, a causa de su gran número. Tuvimos que descartar desde luego, como poco práctico, el orden cronológico, y después de no pocas vacilaciones, hubimos de resolvernos a agruparlos por la materia histórica, en vez de listarlos por sus fechas o por sus procedencias.

El volumen de anexos estará por consiguiente dividido en dieciocho apéndices, cuya lista, por sí sola, constituye un índice de la guerra.

Hela aquí:

ANTES DE LA GUERRA

Apéndice "A". La anexión de Tejas.

" “B”. Propósitos respecto a California.

" "C". Preparativos bélicos en la frontera.

" D”. La misión de Slidell.

" "E". Preliminares de la guerra.

DURANTE LA GUERRA

Apéndice "F". La declaración de guerra.

" "G". Instrucciones a Conner y Taylor.

" “H”. California y Nuevo México.

" "I". Diversas insinuaciones de paz.

" “J”. Regreso a México de Santa Anna y Paredes.

" “K”. El General Scott.

" "L". La misión de Trist.

\section{MISCELÁNEA}

Apéndice "M". Mensajes anuales de Polk.

" "N". Mensajes especiales de Polk.

" “O”. El caso de Yucatán.

" “P”. El tratado de paz y su ratificación.

" “Q”. Miscelánea. ${ }^{7}$ 
Don Luis Cabrera opina que "Polk era un escritor profuso y pesado; pero minucioso y claro. No le importaba repetirse ni aun estropear el lenguaje con tal de expresar sus ideas con claridad". ${ }^{8}$

Además, comenta don Luis, que el interés del libro consiste en presentar "la historia política de aquella guerra, sus propósitos, su desarrollo y sus resultados, tales como iban formulándose en el espíritu del presidente Polk, verdadero autor y realizador del desmembramiento del territorio mexicano". ${ }^{9}$ Hay que decir que su opinión es también muy crítica, respecto a la responsabilidad que a México corresponde en el conflicto, al considerar que de nuestra parte, sólo se dieron "heroicidades suicidas, que no son una lección recomendable a los mexicanos, y detrás de las cuales se traslucían siempre la impreparación, o la indisciplina, o las disensiones de los jefes, o las ambiciones políticas de los caudillos". ${ }^{10}$

\section{LUIS CABRERA, TRADUCTOR DEL DIARIO DEL PRESIDENTE POLK}

\section{Su vida ${ }^{11}$}

Don Luis Cabrera nació el 17 de julio de 1876 en Zacatlán, Puebla, sus padres fueron don Cesáreo Cabrera y doña Gertrudis Lobato.

En esa ciudad cursó la primaria; después, en la ciudad de México, estudió, entre los años de 1899 a 1893, en la Escuela Nacional Preparatoria. Interrumpió los estudios por dos años y en esa época trabajó como maestro de escuela en el estado de Tlaxcala.

En 1896 ingresó a la Escuela Nacional de Jurisprudencia, de la Universidad Nacional de México, y se recibió de abogado en el año de 1901. Para sostener sus estudios, volvió a dar clases y también trabajó como impresor, corrector de pruebas y reportero teatral y taurino en el periódico El Noticioso, y se inició como literato en El Hijo del Ahuizote.

Ejerció su profesión como abogado postulante, primero trabajando para el licenciado Rodolfo Reyes, después asociado con el licenciado An-

8 Ibidem, p. XI.

9 Ibidem, p. IX.

10 Ibidem, p. X.

11 Los datos de la vida y la obra de Luis Cabrera se tomaron, en su mayoría, de Luis Cabrera. Bibliografía. Aspectos de su vida. Páginas escogidas, México, Editorial Cultura, 1951, 129 pp. 
drés Molina Enríquez, y más tarde trabajó en el bufete de abogados de William A. McLaren y Rafael L. Hernández.

Dio clases de derecho civil en la Escuela Nacional de Jurisprudencia, y fue su director en 1912, año en que con motivo de una huelga estudiantil varios profesores y estudiantes dejaron la Universidad para fundar la Escuela Libre de Derecho.

La actividad política de Cabrera fue importante y variada. En 1908 fue uno de los fundadores del Partido Antirreleccionista que conduciría a Madero a la Presidencia de la república. Una vez electo Madero, don Luis presentó su candidatura para diputado, cargo que ganó por el undécimo distrito electoral del Distrito Federal, en donde estaban incluidos San Ángel, Coyoacán y Tlalpan. Formó parte, entonces, de la XXVI Legislatura en la que fue uno de los principales organizadores del Grupo Renovador; volvió a la Cámara en 1917, ahora como diputado de la XXVII Legislatura.

Cuando cayó Madero, Luis Cabrera estaba fuera del país, al cual no regresaría sino hasta el triunfo de la revolución constitucionalista con Carranza. Acompañó al "Primer Jefe" al estado de Veracruz, y participó en la formación de varias leyes revolucionarias expedidas en el mismo lugar. Carranza lo designó como secretario de Hacienda en diciembre de 1914, cargo que desempeñó durante el periodo pre-constitucional, hasta 1917.

Entre 1916 y 1917 fue uno de los integrantes de la comisión mexicana que negoció el retiro de las tropas estadounidenses, de la famosa expedición punitiva, bajo el mando del general Pershing, y regresó a Querétaro, una vez terminada la evacuación de las tropas americanas.

Estuvo nuevamente a la cabeza de la Secretaría de Hacienda, de abril de 1919 hasta la muerte de don Venustiano, en 1920.

A partir de esa fecha se retiró de la política y reasumió la práctica profesional.

\section{Su obra}

La traducción que don Luis Cabrera hizo del diario del presidente Polk, se cuenta entre muchas otras de sus obras.

En las "Notas biográficas" del libro Luis Cabrera, se menciona que "la producción literaria del Lic. Luis Cabrera, es de tres clases: Jurídica, Política y Literaria". ${ }^{12}$ 
La primera clase firmada con su propio nombre, las otras dos con dos distintos nombres de pluma: el de licenciado Blas Urrea y el de Lucas Ribera.

En la última sección del libro antes citado se enumeran las obras de Luis Cabrera:

Primero, "Trabajos jurídicos", en donde se hace referencia a los que fueron publicados, y que están clasificados en "Folletos", que suman treinta y ocho; "Discursos": dos; "Cartas": cuatro y "Artículos": seis.

Después, "Política”, cuya producción está dividida en cuatro partes, "Ediciones": once, "Artículos": ciento veinte, "Discursos": cinco.

Sigue "Legislatura", en donde se incluyen sus palabras publicadas en el Diario de los Debates, por lo que a la XXVI Legislatura corresponde aparecen un total de sesenta y una intervenciones. Por lo que la Legislatura XXVII toca, aparecen sesenta y cinco.

A continuación se listan los discursos pronunciados en la Cámara de Diputados cuando fungió como secretario de Hacienda y Crédito Público, que suman cuatro, a los que se añaden otros, de distintas ocasiones, y que son catorce.

La siguiente clase se refiere a "Cartas" y en ella se enumeran cuarenta y seis.

Siguen los trabajos literarios que incluyen poesías, artículos, discursos, cuentos y traducciones poéticas y de otro género, del inglés, francés, italiano, catalán, alemán, griego, y por supuesto, se incluye en esta parte al Diario del presidente Polk.

Mi colega don Emilio O. Rabasa ha resumido de forma excelente la personalidad, vida y obra de don Luis Cabrera. Don Emilio expresa:

Para conocer la vida y obras completas de Luis Cabrera, hay que hurgar en sus varias y diferentes "vidas":

La de Blas Urrea, el apasionado y permanente escritor político.

La de Lucas Ribera, el literato (traductor, cuentista, poeta y ensayista).

La de, al fin, el licenciado Luis Cabrera, el abogado postulante e incansable batallador, pero también el político actuante-intransigente e irreductible-lealísimo carrancista, el revolucionario entregado, el periodista incendiario, el funcionario honrado, el crítico socarrón, el polemista parlamentario, el diplomático hábil, el maestro universitario, el ejemplar pater familias. ${ }^{13}$ 
El propósito inicial de este estudio fue el de analizar la traducción hecha por don Luis Cabrera de algunos pasajes del Diario del presidente Polk; al redactarlo, el objetivo se convirtió no sólo para recordar guiados por don Luis, la guerra de Estados Unidos de América contra México, sino también para rendirle un homenaje a ese gran mexicano que fue Luis Cabrera. 


\title{
APUNTES PARA LA HISTORIA DE LA GUERRA ENTRE MÉXICO Y LOS ESTADOS UNIDOS
}

\author{
Ricardo MÉNDEZ SILVA*
}

Dedico a Gina y a Rodrigo, a quienes pido que un día recuerden a Margarito Suazo

Este libro, Apuntes para la historia de la guerra entre México y los Estados Unidos, fue publicado en 1848, en el mismo año en el que se firmó el Tratado de Guadalupe Hidalgo, ${ }^{1}$ un aciago dos de febrero. Fue escrito por un grupo preclaro de intelectuales y políticos, quienes incluso habían participado en la guerra, pertenecientes a distintas tendencias y bandos políticos. Persiguieron dejar un testimonio, su interpretación angustiosa, inspirados por la mayor objetividad para analizar la desventura de la patria derrotada. Actualmente, los historiadores mexicanos coinciden en que este libro es la más valiosa aportación, al menos desde el punto de vista mexicano, sobre los sucesos de 1846-1848, abarcándose en ella, por supuesto, acontecimientos anteriores y posteriores a los de esos funestos años. Los autores, como hoy el lector interesado, fueron guiados por el afán de desentrañar la trama histórica que culminó en tan dramático desenlace. Al final de la obra insertan un párrafo que contiene una dedicación personalísima al lector de su posteridad:

El hombre ilustrado que dentro de algún tiempo se encargue de escribir la historia de esta época malhadada, resolverá con más acierto la obra iniciada por el gobierno de Querétaro, y perfeccionada por la representación nacional de 1848. Acaso entonces estos desaliñados, pero exactos apuntes, le servirán de algo para el mejor conocimiento de los sucesos. Este es el único interés que tenemos, la única gloria a la que aspiramos. ${ }^{2}$

* Investigador del Instituto de Investigaciones Jurídicas de la UNAM.

1 El nombre completo del acuerdo es Tratado de Paz, Amistad, Límites y Arreglo Definitivo entre la República Mexicana y los Estados Unidos de América, por el cual México perdió poco más de la mitad de su territorio a cambio de una compensación de quince millones de dólares; comprende otras estipulaciones. Véase Archivo Histórico Diplomático Mexicano, Algunos Documentos sobre el Tratado de Guadalupe, pról. de Antonio de la Peña y Reyes, México, Porrúa, 1971, 413 pp.

2 Apuntes para la historia de la guerra entre México y los Estados Unidos, p. 396. 
Esa aspiración fue enarbolada por los siguientes autores: Ramón Alcáraz, poeta, dramaturgo, periodista y diputado constituyente en 1857; José María Castillo, periodista, diputado constituyente en 1857 y secretario de Gobernación en 1871; Félix María Escalante, poeta y periodista; José María Iglesias, jurista, redactor en jefe de El Siglo XIX, magistrado y ministro de Gobernación y de Justicia; Manuel Payno, secretario de Hacienda, diputado varias veces y senador, lo mismo que poeta, dramaturgo y novelista; Guillermo Prieto, poeta, dramaturgo, periodista, diputado en varias ocasiones, incluso al Constituyente, y ministro de Hacienda; Ignacio Ramírez, periodista, diputado constituyente, ministro de Justicia y Fomento, así como magistrado; Francisco Urquidi, liberal y federalista, en varias ocasiones diputado. En la elaboración del libro participaron también Alejo Barreiro, Manuel Muñoz, Ramón Ortiz, Napoleón Saborio, Francisco Schiafino, Francisco Segura, Pablo María Torrescano, sobre quienes la edición facsimilar en comento no incluye datos biográficos, pero igualmente es de justicia agradecerles sus laboriosos afanes para integrar éste libro testimonial.

La obra colectiva encuentra feliz resolución en un solo texto fluido y uniforme. No se trata de una repartición de capítulos inconexos o con reducida ilación como suele ocurrir con algunas obras colectivas de nuestro tiempo. Existen varias inteligencias en concordia, armonizadas por una mano lúcida que le imprime a la narración continuidad y estilo único. Imposible saber el modo en el que se distribuyeron la tarea para alumbrar los apuntes. Dado que en la época se acostumbraban las tertulias, es dable pensar en la celebración de numerosas e intensas sesiones en las que fueron intercambiadas opiniones, información, juicios, y, a no dudarlo, una gran desolación por los episodios sufridos. Tal como se desprende de las referencias biográficas, fue un puñado de hombres que enlazaron su clara vocación intelectual y artística con su voluntad de acción. Por ello el libro es pródigo en datos sobre la totalidad del transcurrir histórico, lo mismo en el orden internacional que en lo concerniente al suceder interno. En esa época, las comunicaciones eran harto dificultosas, por lo que resulta asombrosa la visión actualizada del acontecer; y más todavía, llama la atención la preocupación que tuvieron por consignar el desarrollo de las batallas, el posicionamiento de las tropas, los giros tácticos durante el fragor de la contienda, las personas involucradas en las mismas, los momentos memorables. Todo entrelazado en la urdimbre política y diplomática general. 
Como eran hombres de cultura, además de la documentación que se acompaña con planos de algunas ciudades afectadas y de los combates sostenidos y láminas con las imágenes de los protagonistas, la obra se encuentra iluminada por una prosa cautivante y pulcra que nunca cae en el dramatismo vano o en recursos inexpresivos. Lo menos que uno piensa al recorrer las páginas es ¡Caray, que bien escribían los del siglo XIX! Claro que eran, como hemos atestiguado, figuras del calibre de Manuel Payno, Guillermo Prieto, Ignacio Ramírez, para no traer a colación otra vez la lista completa de los notables autores.

Llamaron a su libro Apuntes... y con este nombre lo concluyeron, según la transcripción que incluí al principio: "desaliñados apuntes". Según se verá más adelante, hubo quien los calificó de "folleto". Sin embargo, la obra es algo más, mucho más que unos apuntes en su sentido literal (hacer una nota o dibujo ligero), la extensión llega a 404 páginas. Escrito en el apresuramiento de unos cuantos meses, exigió una dedicación fenomenal y una elevada pasión para completar el testimonio. Como ya antes se indicó, la obra se distingue por el relato detallado de acontecimientos que de otra suerte se hubieran perdido. Quizás le nombraron apuntes, por que era de mayor magnitud lo que cada uno de ellos hubiera pretendido narrar de acuerdo con sus vivencias. De todas maneras, el lector de esta reseña retrospectiva no deberá llamarse a engaño con el título de Apuntes para la historia de la Guerra entre México y los Estados Unidos. Es más bien un amplio volumen que nos entrega los sucederes y la atmósfera de aquellos años. Por objetividad, más que por cariño al libro, aunque esto cuente por igual, sostengo que en todos los hogares mexicanos debería tener un sitial de honor. La casa, espacio íntimo de cada quien, debe cimentarse en la benignidad de la memoria colectiva.

Un libro tiene su propia historia, independientemente de la que aborda y recrea en el correr de sus capítulos. La de este libro está mayormente perdida. De la edición facsimilar se rescatan datos sobre la imprenta que la dio a luz: Tipografía de Manuel Payno, hijo, calle de Santa Clara, núm. 23. Es decir, uno de los autores, Manuel Payno, ofreció el taller de impresión. Nada sabemos de los tipógrafos, del corrector de pruebas, de quien seleccionó la portada, etcétera. El segundo dato es más relevante y es parte del aura de este libro, si deviene cierto que los libros tienen su propia luminosidad. La edición facsimilar incluye al inicio la Suprema Orden dirigida por la Secretaría de Estado y del Despacho de Gobernación al gobernador (por las pistas elementales, presumiblemente de Puebla, dato 
que es sugerido por el nombre de la calle de la imprenta, Santa Clara, núm. 23). Está fechada la citada Suprema Orden el 1o. de febrero de 1854 y fue expedida por el ministro de Gobernación, de apellido Aguilar. Después de la catástrofe de 1847 y anexas, ocurrió el eterno retorno de Santa Anna al poder. Entonces, los patrióticos afanes de su "Alteza Serenísima" se sintieron ofendidos por la versión y los juicios de los apuntes. Es un manifiesto rico en adjetivaciones imaginativas contra nuestros amigos los autores, quienes fueron de este modo no sólo apostrofados sino que perdieron empleo y algunos no tuvieron otra salida que el destierro. Por ejemplo, dice: "SAS (Su Alteza Serenísima) manda, para escarmiento de quienes así se permitieron un infame desahogo a sus pasiones, cuando lejos acaso de ser en combate testigos de los acontecimientos, buscarían muchos de ellos una ignominiosa seguridad, que sean desde luego destituidos de todo cargo o empleo que obtengan en la administración pública, y queden sus nombres entregados al desprecio de sus conciudadanos". Más adelante, la mentada suprema orden obliga al decomiso del libro "y ordena S. A. (Su Alteza) que V. E. (Vuestra Excelencia) proceda en el acto de recibir esta nota a recoger todos los ejemplares que existan del folleto de que se trata, así en las imprentas y librerías como en poder de los particulares, a quienes se fijará un término prudente y perentorio, para que los pongan a disposición de las respectivas autoridades políticas, con el fin de que inmediatamente sean entregados al fuego que es el destino que merecen los escritos difamatorios de los timbres de un pueblo magnánimo y que mancillan la memoria de los más ilustres defensores de su integridad e independencia". Antes de la rúbrica, la Orden lleva por lema inspirador la frase "Dios y Libertad".

Triste destino de algunos libros, sufrir la indiferencia de los dueños, ser maltratados, pero el peor es acabar consumidos por el fuego de la venganza y de la intolerancia, actitud fascista en todos los tiempos. Varios ejemplares concluyeron así su efímera existencia, pero algunos sobrevivieron, y en 1970 la Editorial Siglo XXI publicó en edición facsimilar los Apuntes para la historia de la Guerra entre México y los Estados Unidos, dando crédito de honor a los autores y divulgando pasajes invaluables de nuestra historia. Hasta el momento, la editorial ha hecho cinco reimpresiones, la última en 1999.

Para un comentario breve, por las exigencias del tiempo, resulta difícil seleccionar, no digamos algún capitulo sino incluso algún párrafo. Desde los primeros acontecimientos de la guerra, en 1846, aparecen los 
destellos heroicos de los soldados y de la población, y también fatalmente, la impericia de los jefes militares. Una vez fracasada la misión diplomática de John Slidell, enviado plenipotenciario del presidente James K. Polk, quien perseguía no sólo regularizar la situación de Texas, sino tratar la compra de California y Nuevo México, el mandatario estadounidense dio órdenes a Zacharías Taylor de avanzar hacia la zona entre el Río Nueces y el Río Bravo que México sostenía enfáticamente era parte de su territorio y no de Texas, cuya separación y posterior anexión a Estados Unidos de América también desconocía. Fue una manifiesta provocación suscitar la respuesta de México y obtener por la fuerza de las armas lo que el país negaba a través del marchanteo diplomático. Cuando las tropas norteñas se acercaban al Frontón de Santa Isabel, los pobladores dejaron su ranchería y le prendieron fuego para restarle al enemigo utilidad. Momento parecido al que protagonizaron los moradores de Laredo. Una vez consumada la ocupación de la ciudad, emigraron al lado mexicano y fundaron Nuevo Laredo, pero antes de partir al nuevo terruño fueron al cementerio por sus muertos con el fin de llevarlos consigo y hacerlos reposar en tierra mexicana. Es este un sentimiento antropológico ancestral, presente en los fundadores de los asentamientos y las ciudades más antiguas de la humanidad. Para los pioneros de Nuevo Laredo fue su sentido original del patriotismo, el de una nación todavía en ciernes, en promesa vital.

Después de los sucesos del Frontón de Santa Isabel, ocurrieron las escaramuzas del 25 de abril de 1846 en Carricitos, que ocasionó a los norteamericanos pérdidas de setenta hombres, entre heridos y muertos. Este incidente llevó el 11 de mayo a un Polk furibundo a requerir del Congreso estadounidense la declaración de guerra: "después de una larga y continua serie de amenazas, al fin ha invadido (México) nuestro territorio y derramado la sangre de nuestros ciudadanos en nuestro propio suelo". Este párrafo, con el acompañamiento de tambores de guerra, ha sido más difundido a través de la frase "se ha derramado sangre americana en suelo americano" que retumba todavía en los cráneos de todos los fallecidos, mexicanos, norteamericanos, irlandeses, en aquella guerra desnaturalizada, según la calificó el general Winfield Scott, jefe de las fuerzas expedicionarias de Estados Unidos de América. Pero el inconsciente traiciona al presidente estadounidense cuando utiliza la expresión "al fin”. Era lo que buscaba, la reacción mexicana. El Congreso de Estados Unidos de América aprobó la Declaración de Guerra, dos días después, el 
13 de mayo. Así estaban de caldeados los ánimos, el trámite recibió la bendición legislativa de ese fast track decimonónico.

Mientras tanto, durante el 8 y el 9 de mayo había ocurrido la primera batalla importante. Mariano Arista sustituyó a Pedro Ampudia al frente del Ejército del Norte, lo que provocó, de una parte, rivalidades entre el alto mando ${ }^{3} \mathrm{y}$, de otra, pérdida preciosa de tiempo en aquella hora dramática. Cruzó el Río Bravo como respuesta al desplazamiento de Taylor a la zona disputada. Varios connacionales le recriminarían ese movimiento que encendió la mecha de las confrontaciones. No creo que éste sea el reclamo a Arista, hay en cambio otros que se le puedan formular con mayor justificación. El primer combate tuvo lugar en Palo Alto. La artillería estadounidense probó desde el principio su superioridad en alcances y poder destructivo, aunada a una visión estratégica contundente y definida. Nuestros soldados eran masacrados por el bombardeo y pedían la oportunidad de cargar a bayoneta calada con el fin de que su sacrificio no fuera en balde. Bayonetas contra cañones. Fue uno de los actos de heroísmo suicida, más tarde calificados así por Luis Cabrera. La triquiñuela del enemigo de prender fuego a los secos pastizales, remató los ímpetus bélicos de los nuestros, y Arista optó por retirarse a Palma de Guerrero, lugar impropio en términos estratégicos para librar una segunda contienda. Más grave fue que a pesar del avistamiento de las patrullas enemigas, que a las claras avanzaban reconociendo el terreno, el general en jefe no creyó en ningún momento en la posibilidad de un nuevo ataque. Se convenció de éste finalmente, cuando ya había sido derrotado en todas las líneas. Desesperados, los soldados huyeron en tropel, tratando de salvar sus vidas y lanzando un grito desgarrador, recurrente a lo largo de los dos años por venir: ¡traición! Algunos pudieron cruzar el Río Bravo en los chalanes que los habían conducido, pero muchos más perecieron ahogados, por la simple razón de que nadie previó una retirada en circunstancias de urgencia. Los contemporáneos de Mariano Arista no tachan su valor ni honestidad, sólo consignan seca y tristemente los acontecimientos del ocho y nueve de mayo. De todas maneras, después de leer este pasaje, evito caminar por la calle que ostenta su nombre en la ciudad de México.

3 "La antigua rivalidad de ambos revivió más ardiente, enconada con el nuevo motivo de desunión, ocasionada por la mutación del mando del ejército: el espíritu de discordia levantó la cabeza cundiendo rápidamente; y aquellas escandalosas disensiones fueron, como vamos a ver, una de las causas principales de los desastres que principiaron la serie dilatada de nuestras derrotas". Ibidem, p. 36. 
Podríamos entonces detenernos en numerosos episodios, en párrafos, inclusive en frases del libro. Nos encontraríamos momentos protagonizados por el general Miñón en la Batalla de la Angostura que nunca atacó con la caballería a su mando. Toda la vida se la pasarían él y el general Santa Anna reprochándose si había o no recibido la orden para hacerlo. También, la actitud expectante del general Santa Anna en la batalla de Padierna en la que el general Gabriel Valencia comandaba del lado mexicano. Al igual, la pasividad criminal del general Juan Álvarez durante la batalla de Molino del Rey, cuya caballería parecía haber acudido a un día de campo en Chapultepec. Los soldados caían sacrificados sin destino.

Precisamente en ésta última batalla, Guillermo Prieto, en otro libro memorable, Memorias de mis tiempos, salvó a Margarito Suazo de su sacrificio anónimo para pervivir en una modesta inmortalidad, no exenta de tristeza. Relata Guillermo Prieto, también autor de los apuntes:

Margarito Suazo era un artesano humildísimo, que se hizo querer en su Cuerpo de Mina, por su subordinación y bondad, y así se le nombró abanderado. El día de la acción, Margarito se excedió en el cumplimiento del deber. Atropellado por un gran número y hecho una criba a bayonetazos, quedó por muerto, asido a su bandera. Sintiendo que moría, se incorporó, se despojó de su ropa, enredó su bandera a su cuerpo que chorreaba sangre, y expiró. ${ }^{4}$

Saltan algunos comentarios. Se menciona al Cuerpo de Mina. Los batallones de voluntarios se nombraron a sí mismos evocando a héroes de la independencia, uno llevó éste nombre, Independencia, al mando de Agustín Iturbide, hijo y padre de emperadores frustrados, el de Bravos, en honor de Leonardo, Miguel y Nicolás, y el bautizado en recordación de Francisco Javier Mina, del cual fue abanderado Margarito. Todas las hazañas de aquella guerra infausta parecen resolverse en la épica de los niños héroes, y con la leyenda del cadete que desde lo alto del Castillo de Chapultepec se lanza al vacío, se despliega un velo que hace palidecer los horrores de la realidad. Ciertamente existieron y fueron victimados los adolescentes y jóvenes del Heroico Colegio Militar. La mayor parte de ellos acribillados por la espalda, cuando abandonaban el Alcázar. Sus muertes fueron patéticas, más sobresale por su dramatismo la de Agustín

4 Prieto, Guillermo, Memorias de mis tiempos, vol. II: 1840 a 1853, México, Librería de la viuda de C. Bouret, Cinco de mayo 14, 1906, p. 240. 
Melgar. Meses antes del ataque a Chapultepec había sido dado de baja, pero la inminencia de la batalla lo impulsó al lado de sus compañeros. Defendió hasta el final su puesto, incluso pudo ultimar a uno de los atacantes, mas parapetado tras un colchón, fue herido a balazos y abatido por golpes de bayoneta. Atendido en el rudimentario hospital del enemigo, murió al día siguiente, no sin antes sufrir la amputación de una pierna, en medio de padecimientos indecibles. Fernando Montes de Oca fue alcanzado por la fusilería enemiga, y su cuerpo permaneció insepulto durante tres días entre los pastizales del cerro. ${ }^{5}$ Hubo muchas bajas, incuantificables, entre otras, las del Batallón de San Blas y su arrojado comandante, Santiago Felipe Xicoténcatl. Y ya nadie se acuerda de Margarito Suazo..., y eso que en el corredor de entrada al Salón Adolfo López Mateos, de la Residencia Oficial de los Pinos, ubicada en el mismísimo Molino del Rey, se conserva una estela de piedra que recuerda el sitio exacto en el que cayó el 8 de septiembre de 1847 el subteniente Margarito Suazo, defendiendo la bandera del Batallón de Mina.

Correspondió a Nicolás Bravo encabezar la defensa del Castillo de Chapultepec. Lo he nombrado a veces "el último insurgente", no por que fuera en efecto el último de la generación heroica en desaparecer biológicamente, sino por que fue de los primeros en empuñar las armas contra la corona española, y quien, a pesar de los vaivenes políticos de la época, guardó siempre una ejemplar integridad moral. Él simboliza ese arco histórico que se revela en los años diez y culmina en 1848. Es recordado en los anales de nuestra historia por el perdón que concedió a trescientos prisioneros españoles, después de que su padre Leonardo fuera ejecutado a garrote vil en los albores de la independencia. Qué pensaría Nicolás en esos momentos, cuando los estadounidenses bombardeaban sin descanso el Castillo, la última trinchera nacional, sin recibir los refuerzos que angustiosamente solicitaba a Santa Anna. La patria había nacido en 1821 con ingenuos votos de felicidad, y se deshacía fatalmente entre las manos de todos sus contemporáneos; las ilusiones de antaño padecían una penosa regresión hasta la obscuridad de las grutas cercanas a Chichihualco, en donde se ocultaba con su padre y sus tíos en los primeros años de la insurgencia. ${ }^{6}$

5 Romero Flores, Jesús, Chapultepec en la historia de México, México, Secretaría de Educación Pública, 1947, pp. 64 y 65.

6 Véase Ibarra, Héctor, Nicolás Bravo, México, Impresora Juan Pablos, 1952, 125 pp. 
De los apuntes, ahora reviso el capítulo $\mathrm{X}$, dedicado a Veracruz. Todo el norte había ya caído en poder de los estadounidenses, y el presidente Polk dio un golpe estratégico, cerrando la pinza de la invasión a través del ataque a Veracruz, para proseguir a la ciudad de México por la llamada "Ruta de Cortés", tres lustros más tarde recorrida igualmente por los franceses. Desafortunado destino el del puerto, no sólo enfrentaría al invasor enemigo, sino sufriría en carne propia las desavenencias internas. El vicepresidente Valentín Gómez Farías, fiel a su ideario político, y urgido de fondos para sufragar los gastos de la guerra, decidió proclamar la desamortización de los bienes del clero. Nadie duda de la procedencia moral de tal medida, un decenio adelante sería pieza clave en la refundación de la república durante el movimiento de Reforma. Pero en esas horas comprometidas, abrió el insigne liberal un frente adicional que provocó el lamentable alzamiento de los polkos, jóvenes de la alta sociedad, así llamados por una danza en boga que gustaban bailar. Veracruz encaró en soledad el arribo de los marines, sin esperanza de recibir apoyo del gobierno central y sin posibilidad alguna de resistir victoriosamente la acometida del enemigo.

Polk nombró como nuevo comandante en jefe a Winfield Scott. Por un lado metió una cuña amenazante por la costa del Golfo de México y a la vez retiró del mando a Zacarías Taylor, cuya estrella política iba en ascenso y a quien no lograría contener, al punto de que éste lo sucedería en la presidencia. El 9 de marzo de 1847 las tropas enemigas iniciaron el desembarco. El 22 de marzo el enemigo ultimó rendición, y tras la digna y valerosa negativa de los defensores, a las cuatro de la tarde las baterías rompieron fuego a discreción. Los autores de los apuntes reviven esos momentos decisivos: "La lucha está empeñada. ¡Dios salve a la República!". ${ }^{7}$ El bombardeo fue inmisericorde, alcanzó a sitios habilitados de hospitales, a los templos y escuelas, causando inenarrables destrozos y un gran número de muertos y heridos. Cinco días después de iniciado el fuego no se encontraba una casa indemne: "Es un espectáculo terrible el que presenta Veracruz en estos momentos: padres de familia que han perdido sus casas, su fortuna, sus hijos; niños desgraciados que no tienen ya padres; algunos heridos abandonados, sin alimento, hasta sin curación a veces, por que el hospital es el blanco de los proyectiles enemigos; otros, 
arrastrándose por las calles, macilentos y ensangrentados, en busca de los auxilios de que carecen. El pueblo, pobre, hambriento, porque come con la guarnición de los víveres acopiados por el ayuntamiento, y éstos son ya muy escasos: tal es el espectáculo que presenta Veracruz". ${ }^{8}$

Cundió la desesperación el día 27. Los cónsules extranjeros residentes en el puerto, junto con el alcalde segundo, acudieron en comisión parlamentaria a solicitar al enemigo una tregua, con el fin de que pudieran salir los neutrales, y con ellos las mujeres, niños y ancianos. En esas fechas no existía el derecho de la guerra, pero había entre los contendientes prácticas humanitarias en nombre de la conmiseración y del honor militar. Solicitarían piedad para los no combatientes, mientras que los hombres permanecerían en sus puestos, es decir, morirían luchando. La afligida comitiva retornó con la noticia de que el comandante en jefe, Scott, los había ignorado, y que a través de un ayudante había conminado a la rendición incondicional de la plaza y había advertido que dispararía sin dar cuartel sobre quienes se atrevieran a salir. "El peligro con todos sus horrores; esa muerte segura y sin defensa, engalanada con sus arreos de sangre, era el triste porvenir de una población inerme". ${ }^{9}$ A pesar del ultimátum, los cónsules decidieron salir a bandera desplegada cubriendo a sus connacionales, y tras ellos la columna doliente de civiles indefensos. Las escenas de despedida de los defensores y sus familiares son tan emotivas, mueven al llanto humano profundo. Era un adiós definitivo, irremediable, conociendo de antemano el dramatismo del final. Pero las condiciones insostenibles, la falta de parque, la intransigencia del enemigo, la escasez de alimentos, y no obstante que la Guardia Nacional de Veracruz se oponía a la capitulación, llevaron a entregar la plaza. "Todo había acabado para Veracruz". ${ }^{10}$

Entre el dolor padecido y la sangre vertida, brillan actos de magnanimidad luminosa. Los autores rescataron para la posteridad la figura del cónsul de España, don Telésforo González de Escalante, quien ofreció a los que sufrían la intemperie provocada por la guerra, a mujeres, niños y ancianos, el abrigo de su casa, y relatan que su bienandanza por este mundo llegó al grado de alimentarlos y servirlos personalmente. "Séanos lícito consagrarle en estas líneas un testimonio de gratitud por su noble con- 
ducta". ${ }^{11}$ Séanos también lícito a los lectores de hoy obsequiarle una recordación emocionada.

Para concluir, repito, este libro debería ser conocido por todo mexicano. El estudio de nuestra historia se ha concentrado en otras etapas y, a nivel general, la Guerra de Estados Unidos de América contra México se cubre con una simbología evasiva por varias razones, una de ellas, quizás, por que lo traumático del acontecer nos ha impuesto un mecanismo sicológico de defensa, pero todos quienes lucharon, fueron heridos, mutilados, murieron y perdieron a sus seres queridos, demandan el consuelo enaltecedor de nuestra memoria. 
La guerra de conquista que Estados Unidos de América infringió a México para despojarlo de más de la mitad de su territorio ha producido muchas y muy sentidas páginas, para referir el despojo más grande que ha sufrido un país en nuestro continente. Cosa distinta ha sucedido en la unión americana, cuyos historiadores casi no se han ocupado de este suceso que fue el inicio de su consolidación como primera potencia continental, proceso que culminaría en 1898, con la guerra contra España para apoderarse de Cuba.

Es común encontrar, aún en el ámbito universitario, a mexicanos convencidos de que semejante acontecimiento se debió al quehacer de un solo personaje, a quien se le ha convertido en el responsable histórico de estos hechos, Antonio López de Santa Anna. En un juicio simplista, que no corresponde a un análisis histórico, se omite tomar en cuenta la situación política, económica y social de México; la asimetría entre ambos países; la falta de cohesión nacional; la bancarrota del erario y la lucha intestina por el poder entre las oligarquías.

Fueron esas visiones reduccionistas las que llevaron al historiador José C. Valadés a hacer una revisión histórica de estos hechos, con objeto de ubicar a los diversos personajes de nuestra historia en su dimensión real, fuera de adjetivaciones esquemáticas. Valadés escribió primero la obra Santa Anna y la guerra de Texas, y después, La guerra con los Estados Unidos, para explicar la compleja situación que vivía México en el momento que sufrió la injusta invasión y el papel que Santa Anna jugó en esta tragedia nacional.

Para reconstruir el pasado que nos constituye como nación se requiere superar todo maniqueísmo, vencedores y vencidos reclaman la misma dedicación y estudio, para lograr el conocimiento histórico; de otra forma se tiene una visión parcial y fragmentaria. Es indispensable estudiar y diferenciar el hecho histórico de la mitología cívica, acuñada en el proceso de construcción del Estado mexicano, así como del oposicionismo sectario.

* Historiadora, UNAM. 
La profesionalización de la investigación histórica ha llevado a superar el equívoco de identificar a los historiadores con la ideología de los personajes que estudian. Anteriormente muchas fueron las críticas que recibieron quienes estudiaban a los vencidos, en vez de hacer la apología de los vencedores.

Con el mismo sentido de revisionismo histórico que Valadés inició el estudio a las grandes figuras del conservadurismo mexicano como Lucas Alamán y José María Gutiérrez de Estrada, o personajes tan controvertidos como Santa Anna, Porfirio Díaz, Comonfort y Maximiliano; con motivo de conmemorar el ciento cincuenta aniversario de la guerra de conquista del territorio mexicano que perpetró Estados Unidos de América de 1846-1847 publicamos la obra En defensa de la Patria. ${ }^{1}$

La obra reconstruye los hechos históricos, dando cuenta de la guerra y de la situación en México, e incluye la reproducción de documentos e imágenes con objeto de dar una visión integral.

La doctora Josefina Zoraida Vázquez, historiadora que ha dedicado su vida al estudio de este periodo de las relaciones entre México y los Estados Unidos de América, nos ofrece un texto ponderado y maduro. Se incluye también el texto del maestro Reynaldo Sordo, quien ha hecho una importante aportación histórica con el estudio del moderantismo en México, justamente porque en el tiempo de la guerra, los moderados fueron el fiel de la balanza quienes tuvieron bajo su responsabilidad la firma del Tratado de Paz, Amistad y Límites entre México y Estados Unidos de América.

La obra cuenta además con una útil cronología comparada escrita por la historiadora estadounidense y mexicanista, Linda Arnold, y está precedida de un estudio introductorio que contiene el recuento sintético de los hechos. Los fascimilares de los documentos más significativos, así como la obra pictórica que se realizó para recrear estos acontecimientos históricos, completan y enriquecen una edición cuidadosa y bellamente impresa.

La obra lleva el título En defensa de la Patria, que es el lema que se inscribió en las medallas que recibieran los deudos de los mexicanos caídos en esta guerra, en homenaje a todos ellos, así como a los miles de mexicanos que, sin quererlo, perdieron su nacionalidad en aquellos aciagos días, y cuyos descendientes hoy llevan a cabo la reconquista silenciosa de los territorios arrebatados a México. 
Desde que el país logró independizarse de España, las potencias de la época pretendieron ocupar el lugar de la antigua metrópoli o sacar provecho de la nueva nación, por medio de tratados ruinosos a cambio de su reconocimiento. En 1836, el mismo año en que España reconoce finalmente la Independencia, después de un fallido intento de reconquista, Texas se separa de México con el apoyo de Estados Unidos de América.

En 1838, Francia hace un primer intento de intervención con la llamada Guerra de los pasteles; y en 1845, Texas se anexa a la unión norteamericana y empieza a presionar a México para modificar su frontera hacia el sur, desconociendo los límites originales marcados por el Tratado Adams-Onís de 1819 en el que la frontera entre Estados Unidos de América y la Nueva España se fijó en el Río de las Nueces y no en el Río Bravo. Al no lograr su objetivo por presiones diplomáticas, invaden con sus tropas el territorio en disputa, así como los territorios que ambicionaban en el norte del país. Una columna avanza desde el norte hasta la ciudad de México y otra más hace lo mismo desde Veracruz.

Estados Unidos de América había iniciado su expansión, a costa de sus vecinos, después de consumada su independencia. Compraron a los franceses la Louisiana, a los españoles las Floridas, avanzaron en el territorio indio lanzando a esta población al sur y finalmente pusieron su mira en el territorio mexicano.

Desde el final de la época virreinal habían ingresado colonos estadounidenses a Texas. En las primeras décadas del México independiente, prosiguieron su entrada violando las leyes que establecían que los colonos fueran católicos y que no tuvieran esclavos.

El primer embajador de Estados Unidos de América ante México, Joel R. Pointsett, ofreció cinco millones por el territorio de Texas el 25 de agosto de 1829. La propuesta fue rechazada, y se decretó al año siguiente una ley de colonización que prohibía la entrada de colonos norteamericanos. No obstante, ésta continuó.

Al establecerse en México una Constitución centralista en 1836, los colonos establecidos en Texas argumentaron que se rompía el pacto federal de la Constitución de 1824, y se consideraban con el derecho de formar un Estado libre y soberano. El general Samuel Houston organizó la sublevación con armas que obtenía del gobierno estadounidense presidido por Andrew Jackson.

El 1o. de marzo de 1836, Texas proclamó su independencia definitiva de México, y nombró presidente a David G. Burnett y vicepresidente a 
Lorenzo de Zavala. El caudillo militar que fungía como árbitro de la política nacional, Antonio López de Santa Anna, se puso al mando de las fuerzas que harían frente a los rebeldes.

El camino hacia el norte fue largo y penoso. Los soldados, mal armados, sin experiencia, muchos de ellos descalzos y prácticamente desnudos, eran acompañados de mujeres y niños y de otros hombres que eran reclutados conforme se acercaban a San Antonio.

Después de recorrer más de 1,500 kilómetros, se encontraron frente al Álamo, lugar donde estaban pertrechados los texanos. El 4 de marzo de 1836 la plaza fue tomada a sangre y fuego, y los sublevados fueron derrotados y ejecutados por órdenes de Santa Anna. Después, las fuerzas estadounidenses sorprendieron a las mexicanas en las márgenes del río San Jacinto, y Santa Anna fue hecho prisionero.

En Galveston, Santa Anna fue obligado a firmar dos tratados, uno de ellos "secreto", que carecía de validez oficial al no contar con facultades para llegar a ningún acuerdo. Según el primer tratado, el militar mexicano se comprometía a no volver a levantarse en armas contra Texas, mientras que por el segundo se obligaba a tratar de influir en su gobierno para que se reconociera la independencia texana.

Prisionero durante siete meses, Santa Anna fue llevado a Washington ante el presidente Jackson. Por los compromisos que contrajo con el gobierno norteamericano a cambio de su libertad y por sus acciones posteriores durante la propia guerra, se le ha acusado de traición a la Patria y muchos autores le responsabilizan de la derrota que sufrió México, al considerar que ayudó al triunfo del enemigo. ${ }^{2}$

En la carta reservada del almirante Alex Slidell McKenzie a James Buchanan, jefe del Departamento de Estado, contenida en el Diario del presidente Polk; el almirante narra el encuentro que tuvo con Santa Anna en La Habana, donde le manifestó el deseo de Estados Unidos de América de adquirir mediante un tratado "algunas porciones del territorio norte de México consistentes en tierras baldías o escasamente pobladas, y en parte pobladas ya por nativos de Estados Unidos... a cambio de una amplia compensación de dinero en efectivo que serviría para restaurar sus finanzas, consolidar su gobierno e instituciones y cimentar su poder y prosperidad, con tendencias a protegerlo contra futuras usurpaciones y ase-

2 García Cantú, Gastón, Las invasiones norteamericanas en México, México, Editorial Era, 1974, pp. 114 y 115 . 
gurarle la posición entre las repúblicas del nuevo mundo, que el presidente de Estados Unidos desearía verlo ocupar". ${ }^{3}$ Si habían comprado territorio a Francia y a España, por qué no hacerlo con su vecino mexicano que andaba en apuros económicos.

Según Slidell, Santa Anna redactó una nota como respuesta al presidente estadounidense, cuyo original — cosa extraña — fue destruido por él mismo. En este documento, Santa Anna aseguraba que "no vacilaría en hacer concesiones antes que consentir que México estuviera gobernado por un príncipe extranjero que los monarquistas están tratando de elevar (al trono)" y que "prefería un arreglo amistoso a los estragos de la guerra que pueden ser calamitosos para su país... que si el gobierno estimula sus patrióticos deseos, ofrece responder con una paz tal como se ha descrito".

Asimismo, Slidell sostiene que Santa Anna sugería que el general Taylor avanzara "a la ciudad del Saltillo, que es una buena posición, obligando al general Paredes a luchar, puesto que considera fácil su derrocamiento, y hecho esto el General Taylor podría avanzar hacia San Luis Potosí, cuyo movimiento obligará a los mexicanos de todos los partidos a llamar al propio Santa Anna". Más adelante, refiere que le sugiere atacar San Juan de Ulúa y ocupar Tampico, lo cual resultaría muy fácil para el ejército estadounidense.

Finalmente, Slidell señala que Santa Anna pedía que se guardara el mayor secreto sobre esta conversación, "puesto que sus compatriotas, sin apreciar sus benévolas intenciones de librarlos de la guerra y de otros males, podrían formar una opinión dudosa de su patriotismo".

Al no existir el documento original de la nota redactada por Santa Anna, no es posible comprobar que el ex presidente mexicano planeara la derrota del propio ejército que él comandaría en un acto de traición a la Patria.

A partir de que Santa Anna llegó a la ciudad de México el 14 de septiembre de 1846, se corrió el rumor de que había hecho "arreglos secretos" con el gobierno de Estados Unidos de América. En Londres, el periódico The Observer publicó el 4 de octubre que el arreglo "consistía en la restauración del federalismo con garantía norteamericana, frontera en el Bravo, y la California como territorio separado bajo la protección de los Estados Unidos". El diario refiere que Polk había solicitado fondos para sobornar a Santa Anna. ${ }^{4}$

3 El Diario del presidente Polk (1845-1849), recop., trad., pról. y notas de Luis Cabrera, México, Antigua Librería Robredo, 1948, t. II, pp. 303-308.

4 Zorrilla, Luis G., Historia de las relaciones entre México y los Estados Unidos de América, 
El hecho es que después de la derrota de San Jacinto, México no emprendió ninguna otra campaña para recuperar Texas, que fue reconocida como nación independiente por Estados Unidos de América en 1837, por Francia en 1839 y por Inglaterra en 1840. Finalmente, durante la presidencia de James Knox Polk, Texas se anexó a Estados Unidos de América el 29 de diciembre de 1845, "primera forma del imperialismo de la época”, según escribiera don Justo Sierra; y México rompió relaciones diplomáticas con el país del norte.

La guerra era deseada por Estados Unidos de América y aceptada en México por la opinión pública. En diciembre de 1846, Carlos María de Bustamante presentaba un proyecto para fortificar al país y repeler una posible invasión estadounidense, "para hacer una guerra de montaña y destruir los más numerosos ejércitos". 5

Mientras, las acciones expansionistas de Estados Unidos de América continuaban. El presidente Polk quería que México aceptara además del nuevo límite de Texas, vender Nuevo México por 5 millones de pesos y la Alta California por 25. La propuesta fue también rechazada por el gobierno mexicano.

En defensa de su soberanía, el 7 de julio de 1846 México declaró estar en estado de guerra contra Estados Unidos de América. Después de una trágica campaña militar, finalmente se impuso la disciplina del ejército estadounidense y la superioridad de su armamento.

Tras las derrotas del ejército mexicano en Churubusco, los norteamericanos propusieron un proyecto de tratado mediante el cual México debía ceder a Estados Unidos de América no sólo Texas, sino también las Californias, Nuevo México y una franja territorial que correspondía a los estados de Sonora, Chihuahua, Coahuila y Tamaulipas. El gobierno mexicano lo rechazó.

Los norteamericanos procedieron entonces a atacar el Castillo de Chapultepec; en un enfrentamiento a todas luces desigual, murieron los jóvenes estudiantes del Colegio Militar, quienes de acuerdo con los testi-

1800-1958, México, Porrúa, vol. 1, Biblioteca Porrúa, núm. 29, p. 197; y Bustamante, Carlos María de, El nuevo Bernal Díaz del Castillo, o sea Historia de la invasión de los angloamericanos en México, México, Imprenta de Vicente García Torres, 1947, p. 87.

5 Bustamante, Carlos María de, Proyecto de Carlos María de Bustamante para la defensa de México, México, Archivo Histórico de la Secretaría de la Defensa Nacional, Dirección del Archivo Militar, Exped. XI/481.3/2199, fojas 125 y 126. Sección de Operación, diciembre de 1846. 
gos, fueron los últimos soldados que sostuvieron la defensa del castillo. Su muerte simboliza la defensa heroica de la Patria. ${ }^{6}$

El 14 de septiembre de 1847 ondeó en Palacio Nacional la bandera de las barras y de las estrellas, dos días después Santa Anna renunciaba a la Presidencia de la república, y su lugar era ocupado por Manuel de la Peña y Peña. La resistencia de los habitantes de la capital fue valiente, pero la guerra estaba perdida.

Ignacio Manuel Altamirano culpó de la derrota a la falta de preparación de nuestros mandos militares, así como la carencia de patriotismo de las clases privilegiadas. ${ }^{7}$ Manuel Balbontín, al hacer la historia militar de la guerra, señala que dada la condición del ejército mexicano "era absolutamente imposible que México pudiera ganar la guerra" ${ }^{8}$

La derrota fue el resultado no sólo del proceder de un hombre, sino la conjunción de muchos factores adversos que impidieron que nuestro país pudiera triunfar sobre el enemigo invasor. Santa Anna era capaz de traicionar a todo mundo menos a sí mismo, aunque hubiera ofrecido cualquier cosa a los estadounidenses para que lo dejaran libre, nunca lo habría cumplido en contra de su propia vanidad.

Después de tener ocupada la capital de la república casi cinco meses, el gobierno nacional firmó el Tratado de Paz, Amistad y Límites entre México y los Estados Unidos en Guadalupe Hidalgo el 2 de febrero de 1848. México perdió Texas, la porción territorial de Tamaulipas situada entre los ríos Nueces y Bravo, y los estados de la Alta California y Nuevo México, y recibió 15 millones de pesos como indemnización de guerra. El Tratado fue firmado por Bernardo Couto, Miguel Atristáin y Luis G. Cuevas, y por Nicholas P. Trist por parte del gobierno norteamericano.

Los comisionados mexicanos señalaron que "en sustancia - fueron- a recoger los restos del naufragio". Sabían que la pérdida del territorio era inevitable, ya que "los convenios de esta clase realmente se van formando en el discurso de la campaña según se ganen o se pierdan las batallas", y "no hacen sino reducir a formas escritas el resultado final de la Guerra". 9

6 Galeana, Patricia (coord.), Documentos históricos sobre la defensa de Chapultepec, 13 de septiembre de 1847, México, SEGOBAGN, 1997, 144 pp.

7 Vigil, José María, México a través de los siglos, t. V: La Reforma, México, Ballescá y Compañía, Editores, s. f., p. 698.

8 Balbontín, Manuel, Estado militar de la república mexicana en 1846, México, Tipografía de Ignacio Pombo, 1890, pp. 66 y 67.

9 "Exposición de motivos presentada por los comisionados de México", en Peña y Reyes, An- 
Ante las circunstancias, consideraron que había el riesgo de perder la independencia nacional, ${ }^{10}$ y que "la desgracia de México no provendría de falta de territorio".

La firma del tratado tuvo muchos opositores, rechazaban que se sancionara con la firma de un tratado semejante despojo, querían seguir luchando hasta el último hombre. Valentín Gómez Farías, representante de 26 diputados del partido puro, se pronunció en el Congreso por seguir luchando "para no mostrarnos ante el mundo como un pueblo débil, lo que alentaría a nuestro conquistador para volver dentro de pocos años, ya no por otra facción de nuestros terrenos fronterizos, sino por lo demás de nuestro territorio, tratándonos en lo sucesivo, como a las tribus bárbaras que han logrado exterminar". ${ }^{11}$

Se consideró que la firma de semejante tratado nos daría una "paz llena de oprobio y de vergüenza, cuyo resultado en este caso es la esclavitud, es el desprecio universal, es la vergüenza eterna". ${ }^{12}$

No obstante, Justo Sierra al hacer la historia de la guerra, señala que las condiciones en las que se encontraba el país reclamaban la paz. Asegura que sólo quien ignore cuál era la situación de anarquía del país, las tendencias al desmembramiento ya claras en diversos estados, la facilidad con que gran parte de la sociedad aceptaba la tutela americana, podría pensar en continuar la guerra: "un combate más, habría sido un nuevo desastre, parte de Chihuahua, Sonora y Coahuila se habrían perdido... Bajo el imperio de una necesidad suprema, puede y debe una nación ceder parte de su territorio para salvar el resto". ${ }^{13}$

Posteriormente, los pocos artículos que en algo favorecían a nuestro país en el Tratado de Paz fueron pronto derogados, como en el que se comprometía a respetar a los ciudadanos mexicanos que quedaron en el lado ahora estadounidense y que según si les hacía falta mano de obra se les obligaba a adoptar la nacionalidad estadounidense — como en el caso

tonio de la, Algunos documentos sobre el Tratado de Guadalupe y la situación de México durante la invasión americana, México, Secretaría de Relaciones Exteriores, 1930, p. 131.

$10 \quad$ Ibidem, p. 178.

11 Iniciativa de Valentín Gómez Farías en el Congreso Nacional para impedir que se enajene territorio en los tratados de paz, noviembre de 1847, Planes en la nación mexicana, México, Senado de la República, libro IV, 1987, p. 381.

12 Acta de protesta contra la firma de un tratado de paz, 20 de diciembre de 1847, El Republicano Jaliscience, periódico oficial del gobierno, 21 de diciembre de 1847, vol. II, núm. 39.

13 Sierra, Justo, México y su evolución social, México, J. Ballescá y Compañía, 1900, pp. 223 y 224. 
de Nuevo México - o si por el contrario les eran útiles sus tierras se les obligaba a abandonarlas, como en el caso de California, ante el hallazgo de vetas auríferas. También se derogó el artículo en que se comprometían a no lanzar a los indios salvajes al sur, cosa que continuaron haciendo. ${ }^{14}$

La historia de los conflictos entre países fronterizos siempre ha sido azarosa; además, en este caso, México es también la frontera de Iberoamérica. No obstante, la guerra de conquista del territorio mexicano de 1846 a 1848 marcó dramáticamente la historia de las relaciones entre los dos países.

La obra En defensa de la Patria hace una revisión histórica de la guerra de Estados Unidos de América contra México a ciento cincuenta años de distancia, analizando la situación de ambos países y la intervención de los moderados para firmar la paz. La inclusión de los planes de defensa, declaraciones y partes de guerra, mapas, planos de las batallas, grabados y pinturas, nos ofrece una visión integral de esta parte de nuestra historia para intentar su comprensión. 